\title{
The Psychological Impacts During the Initial Phase of the COVID-19 Outbreak, and its Associated Factors Among Pastoral Community in West Omo Zone, South-West Ethiopia, 2020: A Community-Based Study
}

\author{
Nigusie Shifera $\mathbb{D}^{\prime}$ \\ Gebremeskel Mesafint (iD) ${ }^{2}$ \\ Alemayehu Sayih (iD ${ }^{2}$ \\ Gizachew Yilak $^{3}$ \\ Abebaw Molla (iD) 4 \\ Tewodros Yosef (ID) \\ Rahel Matiyas ${ }^{5}$ \\ 'Department of Epidemiology and \\ Biostatics, School of Public Health, Mizan- \\ Tepi University, Mizan-Aman, Ethiopia; \\ ${ }^{2}$ Department of Nursing, College of \\ Medicine and Health Science, Mizan-Tepi \\ University, Mizan-Aman, Ethiopia; \\ ${ }^{3}$ School of Nursing, College of Health \\ Science, Woldia University, Woldia, \\ Ethiopia; ${ }^{4}$ Department of Nutrition, \\ School of Public Health, Mizan-Tepi \\ University, Mizan-Aman, Ethiopia; \\ ${ }^{5}$ Department of Psychology, College of \\ Social Science and Humanity, Mizan-Tepi \\ University, Mizan-Aman, Ethiopia
}

Background: COVID-19 is a global pandemic and a major health crisis affecting several nations. Such outbreaks are associated with adverse mental health consequences to any group of the population. Despite its negative effects, no study has addressed the potential psychological impacts of the COVID-19 outbreak among the pastoral community. This study aims to assess psychological experiences during the early stages of the COVID-19 outbreak and the factors that contributed to it among pastoral community residents in West Omo, South-West Ethiopia.

Methods: A community-based cross-sectional study was carried out from May to June 2020. The study subjects were selected through a multistage sampling technique. Data were collected through face-to-face interviews, and entered into EpiData 3.1, then exported to SPSS version 24 for statistical analysis. The psychological impact was assessed by the Depression, Anxiety and Stress Scale (DASS-21). P-value $<0.20$ during bi-variable analysis was considered as a candidate for multivariable logistic regression. Independent factors of depression, anxiety, and stress were assessed using adjusted odds ratio with $95 \%$ confidence level $\mathrm{s}$ at $\mathrm{P}$-value $<0.05$ cut-off point.

Results: A total of 845 eligible pastoral residents were interviewed, with a $94.4 \%$ response rate. The prevalence of a positive response for anxiety, depression and stress was $30.8 \%$, $26.3 \%$ and $24.4 \%$, respectively. Being female was highly associated with developing anxiety and depression. Anxiety was found to be three times more prevalent among the respondents with $\geq 3$ family members. Furthermore, participants with a history of mental illness, poor social support, and a high perceived life threat were also at a higher risk of experiencing anxiety, depression, and stress.

Conclusion: The prevalence of positive depression, anxiety and stress results were high. As a result, special attention should be paid, by governmental and non-governmental health organizations, to psychosocial and mental health programs for pastoral residentsduring the COVID-19 pandemic.

Keywords: COVID-19, anxiety, depression, outbreak, stress

\section{Introduction}

Coronaviruses are a large family of viruses that can cause a range of illnesses, ranging from the common cold to more severe illnesses. ${ }^{1}$ Several types of coronaviruses are circulating in animals that have not yet been infected human beings. The
Correspondence: Nigusie Shifera Biostatics, School of Public Health, MizanTepi University, Mizan-Aman, Ethiopia Email nigusieshifera@gmail.com 
2019 coronavirus disease (COVID-19) is an emerging disease caused by a newly discovered coronavirus (SARS-CoV-2), a new strain of coronavirus that has not been previously seen in humans beings. ${ }^{1,2}$

Pastoralism is a culture, livelihoods system and extensive use of rangelands. It is the primary production method used in arid and semi-arid dry land environments. ${ }^{3}$ Pastoral groups account for $10 \%$ of Ethiopia's total population and $61 \%$ of the total land mass, $97 \%$ of them found in low land areas of Afar, Somali, Oromia, and SNNPR. ${ }^{3,4}$ Pastoral areas in Ethiopia are characterized by frequent drought with high livestock mortality which often results in threatening the viability of pastoral livelihood, famine, psychological harm and death in the human population. ${ }^{5,6}$ They are the most marginalized group of people in Ethiopia. Even by the standard of Ethiopia, pastoral areas have the lowest access for basic public services such as education, human health services and infrastructures (roads, telephone, markets) are poorly developed. ${ }^{5,7}$

In December 2019, an outbreak of severe acute respiratory syndrome coronavirus infection occurred in Wuhan, Hubei Province, has been evolving rapidly across China and several nations. ${ }^{8,9}$ WHO declared this outbreak of COVID-19 a public health emergency of international concern on 30 January 2020, posing a high risk to countries with weak health systems, and declared the outbreak a pandemic on 12 March $2020 .{ }^{10}$ Most people infected with the COVID-19 virus will experience mild to moderate respiratory illness, ${ }^{11,12}$ however the elderly and those who have underlying medical problems are experiencing serious illness. ${ }^{11-13}$

By 17 July 2019, over 12 million cases had been confirmed, nearly 4 million recovered cases, and over 2.5 million confirmed deaths had been recorded worldwide. ${ }^{14}$ In Africa there were over four million confirmed cases, nearly two million recovered cases and five hundred thousand reported deaths. The most affected countries were Egypt, South Africa, Morocco and Ethiopia. ${ }^{15}$

A large body of evidence ties social isolation and loneliness to poor mental health, and recent data revealed that substantially more people who were sheltering (47\%) experienced negative mental health effects as a result of concern or stress linked to the coronavirus. ${ }^{16}$ Since older adults and families of teenagers are already at risk of depression and suicidal ideation, the negative mental health consequences of social isolation may be more pronounced. ${ }^{17}$ During the initial COVID-19 outbreak in China, a survey found that $53.8 \%$ of respondents rated the outbreak's psychological effect as moderate to extreme, with $16.5 \%$ reporting moderate to severe depression, $28.8 \%$ reporting moderate to severe anxiety, and $8.1 \%$ reporting moderate to severe stress. ${ }^{18}$

A systematic review and a meta-analysis were conducted to examine the overall prevalence of psychological health outcomes during COVID-19 from seven databases indicated, the pooled prevalence of primary psychological outcomes was $26 \%$, Moreover the pooled prevalence for symptoms of PTSD, anxiety, stress and depression was $33 \% 28 \%, 27 \%$, $22 \%$, respectively. ${ }^{19}$ Another similar study in Africa also showed the pooled prevalence of anxiety in 27 studies was $37 \%$, depression in 24 studies was $45 \%$ and insomnia in nine studies was $28 \%$. The pooled prevalence rates of anxiety, depression, and insomnia in North Africa (44\%, 55\%, and $31 \%$, respectively) are higher than the rates in sub-Saharan Africa (31\%, 30\%, and $24 \%$, respectively). ${ }^{20}$

ue to repeated broadcasting the 'stay at home' message by governments of countries around the world, individuals' mobility to different working places, learning, and religious institutions (schools, colleges, universities, and churches) has been continually limited. Furthermore, the factors such as having limited interactions, marginalization, poor infrastructure, and complete isolation of individuals will have a negative impact on the well-being of mental health. ${ }^{21}$

Different studies have been carried out in Ethiopia to assess the mental health impact of the COVID-19 outbreak. ${ }^{22,23}$ However, none of these studies have been done among the pastoral community. So this study aimed to assess the psychological impacts during the initial phases of COVID-19 outbreak among the pastoral community of West Omo zone, south-west Ethiopia. Determining the mental health impact of the COVID-19 outbreak among the community is crucial to developing strategies for the pastoral community to minimize the outbreak related to mental health consequences.

\section{Methods and Materials}

\section{Study Setting, Design and Period}

Cross-sectional study in pastoral community of West Omo zone was conducted from May 1st, 2020 up to June 15, 2020. The West Omo zone is a newly formed zone of the South Nation Nationalities and Peoples of Ethiopian Regional State, with seven districts and 116 kebeles (112 rural and 4 urban), with a total population of 272,943 people, accounting for $12 \%$ of the regional population, and inhibited by a pastoral group of 135, 025 (49.47\%) 
males, $137,918(50.53 \%)$ rural residents, and $243,=738$ $(89.3 \%)(10.7 \%)$. The total number of households is 55,703 , among them more than $60 \%$ were the pastoral community. In terms of health facilities, this zone has two hospitals, 13 health centers, and nineteen-four health posts, giving it a basic health service coverage of $90 \%$ and health center and health post coverage of $98 \%$ and $90 \%$, respectively. It also has one prison facility and nine detention centers.

\section{Population}

All permanently residing pastoral people aged $\geq 18$ years in the selected zones.

\section{Study Population}

All permanently residing pastoral people aged $\geq 18$ years in the selected zone who full fill the eligibility criteria.

\section{Eligibility Criteria}

Participants who were resident for a minimum of six months, and age 18 years and older were included in the study. But those who were critically ill and unable to give a response during data collection time were excluded.

\section{Sample Size Determination and Sampling Procedure}

The single population proportion formula is used to calculate sample size. Since no studies have been carried out on the psychological effects of COVID-19 and its related factors among the pastoral community in Ethiopia, we took $50 \%$ to determine the sample size. Considering assumptions of reliability coefficient of 1.96 , degree of precision 0.05 , with a $10 \%$ non-response rate and a design effect of 2 , the final sample size became 845 .

The study subjects were chosen using a multistage sampling technique. First, the primary sampling units (woreda/districts), in which the four five pastoral districts were selected using the lottery method. Second, the secondary sampling units (Kebele), from each selected districts' $30 \%$ pastoral kebeles were selected using the lottery method.

After selecting pastoral kebeles, the fourth sampling units (households) were identified taking list of households from health extension workers' as sampling frame. Using population proportion to size (PPS) formula, the final sample size was proportionally allocated to each selected kebeles. Finally, eligible study participants were selected using systematic sampling method. The overall sampling procedure is found in Supplementary Figure 1. The lottery method was used when there was more than one eligible participant in a single household.

\section{Study Variables}

The Psychological impact (Anxiety, Depression, Stress) was the dependent variable whereas, Socio-demographic (age, maternal status, education level, occupation, ethnicity and religion, income), Clinical factors (comorbid mental illness, childhood traumatic experience, family mental illness history, using privative measure, having suggestive symptom and comorbid medical illness), Psychosocial factors (social support, substance use history and having perceive life threat) were the independent variables.

\section{Operational Definitions of Variables}

Depression: A DASS-D score of 10 or higher suggests the existence of depression. ${ }^{24}$

Anxiety: A DASS-D score of 8 or higher suggests the existence of anxiety. ${ }^{24}$

Stress: A DASS-D score of 15 or higher suggests the existence of stress. $^{24}$

Social Support: Oslo a three-item questionnaire with a sum score scale ranging from 3 to 14 , with three categories: weak support 3-8, moderate support 9-11, and good support $12-14 .^{25}$

Perceive life threat: was measured using perceived life threat scale having possible scores ranging from Low perceived stress - scores ranging from $0-13$ on PSS; moderate perceived stress - scores ranging from 14-26 on PSS; and high perceived stress -scores ranging from $27-40$ on PSS. $^{26}$

Substance use: use of chat, alcohol, cigarette smoking, or others at least once in the last three months.

\section{Data Collection Tools and Procedure}

The English version validated data collection tools (DASS, Oslo-3 item social support scale, ASSIST) were adopted and widely used in Ethiopia. After adopting these tools translation to the national language of Ethiopia (Amharic) was done to ensure common understanding and consistency. The data were collected via interview administered questionnaires by nine trained health professionals and three supervisors. The questionnaire was pretested among $5 \%$ of the sample size in the districts (woredas) which 
were out of the selected study areas. After the pretest, the questionnaires coherence and skip pattern were corrected.

Outcome variables, Depression, Anxiety and stress were assessed by DASS-21 which is adapted in our country. Depression, anxiety and stress were collected by DASS which has 21 items and 7 items for each. It has been widely used in Ethiopia to assess the emotional state of depression, anxiety and stress; it is Likert scale which ranges from 0 to 3 . The sum scores of 10 and above is indicative of depression, 8 and above are indicative of anxiety and 15 and above is for stress. ${ }^{24}$

Social support was assessed through Oslo-3 item social support scale, the sum score scale ranging from 3-14, which has three categories: poor support 3-8; moderate support 9-11; and strong support $12-14 .^{25}$ Perceive life threat will be measured using perceived life threat scale having possible scores ranging from 0 to 40 with a 5 -point Likert scale $(0=$ never, $1=$ almost never, $2=$ sometimes, 3 = fairly often, $4=$ very often). Low perceived stress scores ranging from $0-13$ on PSS; moderate perceived stress - scores ranging from 14-26 on PSS; and high perceived stress - scores ranging from 27-40 on PSS. ${ }^{26}$

ASSIST, a WHO-developed brief screening questionnaire, was used to determine substance-related factors. This tool is used to determine the participant's current use of psychoactive substances. Current Substance use was those who had a substance use of history for the last three months, for non-medical purposes.

\section{Data Quality Assurance}

The data collection tools were written in English, then translated into Amharic (the national language) and then back to English to ensure consistency. A pretest was done among $5 \%$ of study sample size. Three days training was given for nine data collectors and three supervisors regarding study objectives, content, context and filling of questionnaires, interviewing technique, household selection method and respondents approaching technique. Every day, a supervisor reviewed the completeness of the collected data, and investigators kept track of the total data set. Until entering the data into EpiData 3.1, the completeness of the data was reviewed, and data coding and cleaning were done by cross-checking the printout data for potential errors. Furthermore, descriptive analysis was used to search for missing values and outliers. Furthermore, good relationships using a respectful approach and encouraging gestures were made during the data collection process.

\section{Data Processing and Analysis}

First data were coded, cleaned and entered in to Epi-Data version 3.1, then exported to SPSS version 23 statistical software for analysis. Frequency, charts, and graphs were used to display the descriptive statistics. Logistic regressions were used and those independent variables that were statistically significant with a p-value of $<0.20$ and $95 \%$ confidence level at the bivariate level were included in the multivariate logistic regression model to identify independent factors affecting depression, anxiety, and stress.

The model was built using a backward likelihood ratio with a 0.1 probability of exclusion. The Hosmer Lemeshow goodness of fit test, which considers good fit at P-value $>0.05$, was used to verify the final model's goodness of fit. Finally, independent predictors of depression, anxiety, and stress were established using a P-value of 0.05 as a cut-off point, and the strength of the correlation was evaluated using AORs with 95\% confidence levels.

\section{Results}

\section{Socio-Demographic Characteristics}

The study interviewed a total of 798 qualified participants, with a $94.4 \%$ response rate. The mean $( \pm \mathrm{SD})$ age of the respondents were 31.80 [10.70]. Slightly above three quarters of $622(77.9 \%)$ study participants were rural residents. A similar proportion of 347 (43.5\%) and $341(42.7 \%)$ of the total participants were married and single, respectively. Slightly more than half $(429 ; 53.8 \%)$ of respondents were male [Table 1].

\section{Clinical and Substance Use Related Characteristics of Respondent's}

From all the study participants about 102 (12.8\%), 97 (12.2\%), 117 (14.7\%), and $569(71.3 \%)$ of them had history of mental illness, history of trauma in childhood, history of chronic medical illness and have used any specific preventive measures respectively. Regarding to their history of substance use, less than half of 356 (44.6\%) and about $228(28.6 \%)$ of the total respondents used alcohol and khat, respectively [Table 2].

\section{Mental Health Related Characteristics of Participants'}

The prevalence of positive for anxiety, depression and stress among the pastoral community were 246 (30.8\%) 
Table I Socio-Demographic Characteristics of Participants Among Pastoral Community Residents in West Omo Zone, South-West Ethiopia, 2020 (N=798)

\begin{tabular}{|c|c|c|}
\hline Variables & Frequency $(\mathbf{N})$ & Percent (\%) \\
\hline \multicolumn{3}{|l|}{ Place of residence } \\
\hline Urban & 176 & 22.1 \\
\hline Rural & 622 & 77.9 \\
\hline \multicolumn{3}{|l|}{ Sex } \\
\hline Male & 429 & 53.8 \\
\hline Female & 367 & 46.2 \\
\hline \multicolumn{3}{|l|}{ Marital status } \\
\hline Single & 341 & 42.7 \\
\hline Married & 347 & 43.5 \\
\hline Others* & 110 & 13.8 \\
\hline \multicolumn{3}{|l|}{ Religion } \\
\hline Orthodox & 414 & 51.9 \\
\hline Muslim & 228 & 28.6 \\
\hline Protestant & 147 & 18.4 \\
\hline Other** & 9 & 1.1 \\
\hline \multicolumn{3}{|l|}{ Educational status } \\
\hline Not able to read and write & 311 & 39.0 \\
\hline Able to read and write & 193 & 24.2 \\
\hline Primary $(I-8)$ & 149 & 18.7 \\
\hline Secondary $(9-12)$ & 90 & 11.3 \\
\hline College and above & 55 & 6.9 \\
\hline \multicolumn{3}{|l|}{ Ethnicity } \\
\hline Kaffa & 348 & 43.6 \\
\hline Amhara & 162 & 20.3 \\
\hline Bench & 113 & 14.2 \\
\hline Tigre & 61 & 7.6 \\
\hline Oromo & 60 & 7.5 \\
\hline Others*** & 54 & 6.8 \\
\hline \multicolumn{3}{|l|}{ Occupational } \\
\hline Farmer & 266 & 33.3 \\
\hline Merchant & 136 & 17.0 \\
\hline Housewife & 135 & 16.9 \\
\hline Gov't Employee & 71 & 8.9 \\
\hline Student & 56 & 7.0 \\
\hline Daily Worker & 57 & 7.1 \\
\hline Others $* * * *$ & 77 & 9.6 \\
\hline \multicolumn{3}{|l|}{ Family Size } \\
\hline One & 289 & 36.2 \\
\hline Two & 235 & 29.4 \\
\hline Three or more & 274 & 34.3 \\
\hline \multicolumn{3}{|l|}{ Monthly income (ETB) } \\
\hline$<2000$ & 324 & 40.6 \\
\hline$\geq 2000$ & 474 & 59.4 \\
\hline
\end{tabular}

Notes: *Separated, Divorced and Widowed, **Catholic, Jobs, ***Sheka, Wolayta, *****No jobs, private employee.
Table 2 Clinical- and Substance-Related Characteristics of Respondent's Among Pastoral Community Residents in West Omo Zone, South-West, Ethiopia, 2020 (N=798)

\begin{tabular}{|l|l|l|}
\hline Variables & Frequency & Percent \\
\hline $\begin{array}{l}\text { History of mental illness } \\
\text { Yes }\end{array}$ & 102 & 12.8 \\
No & 696 & 87.2 \\
\hline $\begin{array}{l}\text { History of trauma in childhood } \\
\text { Yes }\end{array}$ & 97 & \\
No & 701 & 12.2 \\
\hline $\begin{array}{l}\text { Family history of mental illness } \\
\text { Yes }\end{array}$ & 115 & 87.8 \\
\hline No & 683 & 85.4 \\
\hline $\begin{array}{l}\text { Use COVID-19 preventive measure } \\
\text { Yes }\end{array}$ & 569 & 71.3 \\
No & 229 & 28.7 \\
\hline History of Chronic medical illness & & \\
Yes & 122 & 15.3 \\
No & 676 & 84.7 \\
\hline Alcohol & & \\
Yes & 356 & 44.6 \\
No & 442 & 55.4 \\
\hline Khat & & \\
Yes & 228 & 28.6 \\
No & 570 & 71.4 \\
\hline
\end{tabular}

with $95 \% \mathrm{CI},{ }^{27,34} 210(26.3 \%)$ with $95 \% \mathrm{CI},{ }^{23,29}$ and 195 (24.4\%) with $95 \% \mathrm{CI}^{21,27}$ respectively [Figure 1].

\section{Factor Associated with Depression}

In a bi-variable binary logistic analysis variables like; sex, social support, marital status, perceived life threat, history of mental illness, history of chronic medical illness, alcohol and khat use were the factors found to be significantly associated with depression among participants towards COVID-19 outbreak.

Being female, social help, perceived life threat, and history of mental illness were found to be statistically significant in association with depression in multivariable logistic regression variables with $\mathrm{p}$-values less than 0.05 .

The odds of developing depression during the COVID19 outbreak among female respondents were almost twice as highthan for males $(\mathrm{AOR}=2.09,95 \% \mathrm{CI}=[1.42$, 3.09]). Participants who had poor and moderate social support were almost four and two times more likely to 


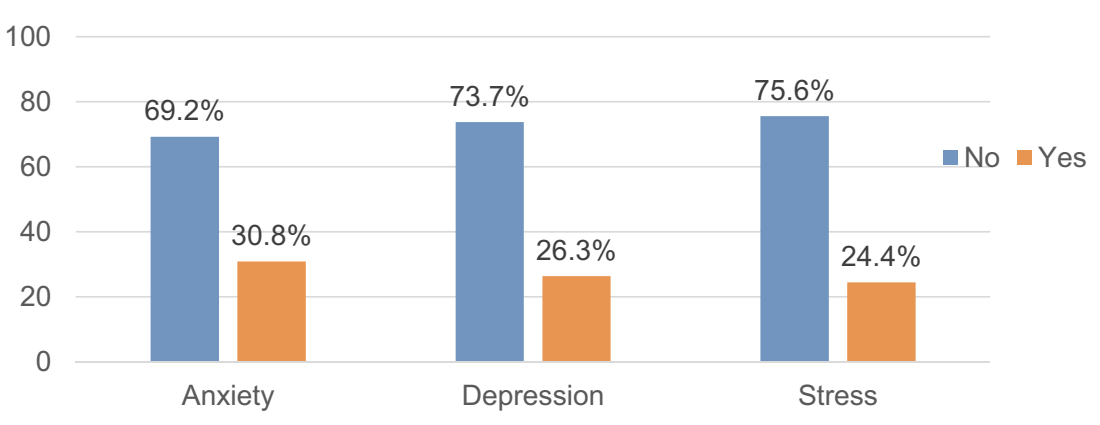

Figure I Psychological impact of the participants' towards the coronavirus outbreak among pastoral community residents in south-west Ethiopia, 2020 (N=798).

have depression during the COVID-19 outbreak than those with strong social support $(\mathrm{AOR}=3.96,95 \% \mathrm{CI}=[2.17$, $7.23]$ and $\mathrm{AOR}=1.99,95 \% \mathrm{CI}=[1.04,3.80])$.

The odds of having depression during the COVID-19 outbreak among respondents who have high and medium perceived life threat were six and three times higher when compared to those who have low perceived life threat $(\mathrm{AOR}=5.60,95 \% \mathrm{CI}=[2.98,10.53])$ and $(\mathrm{AOR}=$ $2.61,95 \% \mathrm{CI}=[1.32,5.15])$. Respondents with a history of mental illness were five times more likely than those without a history of mental illness to be depressed during the COVID-19 outbreak (AOR $=4.97,95 \% \mathrm{CI}=[2.95$, 8.36]) (Table 3).

\section{Factors Associated with Anxiety}

Variables such as sex, family size, marital status, social support, perceived life threat, history of mental illness, history of chronic medical illness, and khat use were found to be significantly correlated with probable anxiety among COVID-19 outbreak participants in a bi-variable binary logistic analysis.

From multivariate binary logistic regression only variables (sex, family size, poor social support, history of mental illness and high perceive life threat) were statistically significant with positive anxiety during the COVID19 outbreak with a p-value less than 0.05 .

The odds of having positive anxiety during the COVID-19 outbreak among respondents who have more than or equal to three and two family members in the household is almost three and two times higher when compared to those who have one member in the family $(\mathrm{AOR}=3.01,95 \% \mathrm{CI}=[1.95,4.65]$ and $\mathrm{AOR}=1.70$, $95 \% \mathrm{CI}=[1.07,2.70])$. Female respondents were almost two times more likely to have positive anxiety towards the COVID-19 outbreak than men $(\mathrm{AOR}=2.35,95 \% \mathrm{CI}=$ $[1.63,3.40])$. Participants who have poor and moderate social support were almost four and two times more likely to have anxiety towards the COVID-19 outbreak than those with strong social support $(\mathrm{AOR}=3.96,95 \% \mathrm{CI}=$ $[2.17,7.23]$ and $\mathrm{AOR}=1.99,95 \% \mathrm{CI}=[1.04,3.80])$.

The odds of having positive anxiety during the COVID-19 outbreak among respondents who have high and medium perceived life threat were five and two times higher as compared to those who have low perceived life threat $(\mathrm{AOR}=4.75,95 \% \mathrm{CI}=[2.76,8.18]$ and $\mathrm{AOR}=$ $2.05,95 \% \mathrm{CI}=[1.15,3.67])$. Respondents with a history of mental illness were four times more likely have anxiety towards the COVID-19 outbreak than those who had no history of mental illness (AOR $=4.04,95 \% \mathrm{CI}=[2.40$, 6.79]) [Table 4].

\section{Factor Associated with Stress}

On bivariate analysis, different variables such as; sex, family size, social support, history of mental illness, history of chronic medical illness, perceive life threat, monthly income, alcohol and khat use were the factors found to be significantly associated with positive stress among participants towards the COVID-19 outbreak on bi-variable analysis. The result of multivariable analysis showed that social support, history of mental illness, and perceive life threat use were found to be statistically significant at $\mathrm{p}$-value less than 0.05 .

Respondents who had poor social support were almost six times more likely to have positive stress towards COVID-19 outbreak than those who had strong social support $(\mathrm{AOR}=5.74,95 \% \mathrm{CI}=[2.98,11.04])$. The odds of having stress during the COVID-19 outbreak among respondents who have high perceived life threat were seven times higher compared to those who have low perceived life threat $(\mathrm{AOR}=6.88,95 \% \mathrm{CI}=[3.63$, 13.03]). Respondents with a history of mental illness were four times more likely to have stress towards the 
Table 3 Factors Associated with Depression During the COVID-19 Outbreak of the Participants Among the Pastoral Community in West Omo Zone, South-West Ethiopia, $2020(\mathrm{~N}=798)$

\begin{tabular}{|c|c|c|c|c|}
\hline \multirow[t]{2}{*}{ Variables } & \multicolumn{2}{|c|}{ Depression } & \multirow[t]{2}{*}{ COR at $95 \% \mathrm{Cl}$} & \multirow[t]{2}{*}{ AOR at $95 \% \mathrm{Cl}$} \\
\hline & No (\%) & Yes (\%) & & \\
\hline \multicolumn{5}{|l|}{ Sex } \\
\hline Male & $343(80.0)$ & $86(20.0)$ & $1.00^{+}$ & $1.00^{+}$ \\
\hline Female & $245(66.4)$ & $124(33.6)$ & $2.0 \mathrm{I}(1.46-2.78)$ & $2.09(1.42-3.09)^{*}$ \\
\hline \multicolumn{5}{|l|}{ Family Size } \\
\hline One & $236(81.7)$ & $53(18.3)$ & $1.00^{+}$ & $1.00^{+}$ \\
\hline Two & $172(73.2)$ & $63(26.8)$ & $1.63(1.07-2.46)$ & $1.31(0.80-2.12)$ \\
\hline Three and more & $180(65.7)$ & $94(34.3)$ & $2.32(1.57-3.43)$ & $1.53(0.96-2.41)$ \\
\hline \multicolumn{5}{|l|}{ Marital status } \\
\hline Single & $254(74.5)$ & $87(25.5)$ & $1.00^{+}$ & $1.00^{+}$ \\
\hline Married & $266(76.7)$ & $81(23.3)$ & $0.88(0.62-1.25)$ & $0.70(0.46-1.06)$ \\
\hline Others & $68(61.8)$ & $42(38.2)$ & $1.80(1.14-2.84)$ & $1.46(0.83-2.58)$ \\
\hline \multicolumn{5}{|l|}{ Social Support } \\
\hline Poor & $215(59.2)$ & $148(40.8)$ & $6.04(3.55-10.27)$ & $3.96(2.17-7.23)^{*}$ \\
\hline Moderate & $215(83.0)$ & $44(17.0)$ & $1.79(1.00-3.22)$ & $1.99(1.04-3.80)^{*}$ \\
\hline Strong & $158(89.8)$ & $18(10.2)$ & $1.00^{+}$ & $1.00^{+}$ \\
\hline \multicolumn{5}{|c|}{ Perceived life threat } \\
\hline Low & $168(92.3)$ & $14(7.7)$ & $1.00^{+}$ & $1.00^{+}$ \\
\hline Medium & $227(82.8)$ & $47(17.2)$ & $2.48(1.32-4.66)$ & $2.61(1.32-5.15)^{*}$ \\
\hline High & 193(56.4) & $149(43.6)$ & $9.26(5.15-16.63)$ & $5.60(2.98-10.53)^{*}$ \\
\hline \multicolumn{5}{|c|}{ History of mental illness } \\
\hline Yes & $34(33.3)$ & $68(66.7)$ & $7.80(4.97-12.25)$ & $4.97(2.95-8.36)^{*}$ \\
\hline No & $554(79.6)$ & $142(20.4)$ & $1.00^{+}$ & $1.00^{+}$ \\
\hline \multicolumn{5}{|c|}{ History of medical illness } \\
\hline Yes & $75(61.5)$ & $47(38.5)$ & $1.97(1.31-2.95)$ & $1.53(0.92-2.56)$ \\
\hline No & $513(75.9)$ & $163(24.1)$ & $1.00^{+}$ & $1.00^{+}$ \\
\hline \multicolumn{5}{|l|}{ Alcohol use } \\
\hline Yes & 254(7I.3) & $102(28.7)$ & $1.24(0.90-1.70)$ & $1.29(0.87-1.92)$ \\
\hline No & $334(75.6)$ & $108(24.4)$ & $1.00^{+}$ & $1.00^{+}$ \\
\hline \multicolumn{5}{|l|}{ Khat use } \\
\hline Yes & $158(69.3)$ & $70(30.7)$ & $1.36(0.96-1.91)$ & $1.28(0.84-1.95)$ \\
\hline No & $430(75.4)$ & $140(24.6)$ & $1.00^{+}$ & $1.00^{+}$ \\
\hline
\end{tabular}

Notes: *Adjusted for all significant variables $\mathrm{p}<0.05,1.00^{+}$Reference Category.

COVID-19 outbreak than their counterparts $(\mathrm{AOR}=3.63$, $95 \% \mathrm{CI}=[2.15,6.12])($ Table 5$)$.

\section{Discussion}

The current research looked at the pastoral community's psychological effects (depression, anxiety, and stress) as well as related causes. The COVID-19 epidemic has been declared a global public health emergency, and this crisis has a mental health effect on the entire population. The WHO urged taking a preventive measure to tackle the negative impact of the spread of COVID-19 on individual mental health and well-being. ${ }^{5}$

The prevalence of positive anxiety, depression, and stress were $30.8 \%, 26.3 \%$, and $24.4 \%$, respectively. Our findings are consistent with previous findings of studies conducted during the pandemic in Saudi Arabia, which reported that the prevalence of depression and stress was $28 \%$ and $22 \%$, respectively. ${ }^{27}$ The prevalence of anxiety was in line with a study conducted in Spain $(32 \%)^{28}$ and systematic review and meta-analysis reported $28 \%{ }^{19}$ 
Table 4 Factor Associated with Anxiety Among Participants' Towards the COVID-19 Outbreak Among Pastoral Community Residents in South-West Ethiopia, 2020 ( $N=798)$

\begin{tabular}{|c|c|c|c|c|}
\hline \multirow[t]{2}{*}{ Variables } & \multicolumn{2}{|c|}{ Anxiety } & \multirow[t]{2}{*}{ COR at $95 \% \mathrm{CI}$} & \multirow[t]{2}{*}{ AOR at $95 \% \mathrm{Cl}$} \\
\hline & No (\%) & Yes (\%) & & \\
\hline \multicolumn{5}{|l|}{ Sex } \\
\hline Male & $33 I(77.2)$ & $98(22.8)$ & $1.00^{+}$ & $1.00^{+}$ \\
\hline Female & $221(59.9)$ & $148(40.1)$ & $2.26(1.66-3.07)$ & $2.35(1.63-3.40)^{*}$ \\
\hline \multicolumn{5}{|l|}{ Family Size } \\
\hline One & $238(82.4)$ & $5 I(17.6)$ & $1.00^{+}$ & $1.00^{+}$ \\
\hline Two & $165(70.2)$ & $70(29.8)$ & $1.98(1.31-2.98)$ & $1.70(1.07-2.70)^{*}$ \\
\hline Three and More & $149(54.4)$ & $125(45.6)$ & $3.91(2.66-5.75)$ & $3.01(1.95-4.65)^{*}$ \\
\hline \multicolumn{5}{|l|}{ Marital status } \\
\hline Single & $239(70.1)$ & $102(29.9)$ & $1.00^{+}$ & $1.00^{+}$ \\
\hline Married & 247(7I.2) & $100(28.8)$ & $0.94(0.68-\mid .31)$ & $0.76(0.52-1.13)$ \\
\hline Others & $66(60.0)$ & $44(40.0)$ & $1.56(1.00-2.44)$ & $1.12(0.65-1.95)$ \\
\hline \multicolumn{5}{|l|}{ Social Support } \\
\hline Poor & $200(55.1)$ & 163(44.9) & $4.13(2.63-6.47)$ & $2.32(1.38-3.90) *$ \\
\hline Moderate & $205(79.2)$ & $54(20.8)$ & $1.33(0.8 I-2.19)$ & $1.35(0.77-2.35)$ \\
\hline Strong & $147(83.5)$ & $29(16.5)$ & $1.00^{+}$ & $1.00^{+}$ \\
\hline \multicolumn{5}{|c|}{ Perceived life threat } \\
\hline Low & $161(88.5)$ & $2 I(I I .5)$ & $1.00^{+}$ & $1.00^{+}$ \\
\hline Medium & $217(79.2)$ & $57(200.8)$ & $2.01(1.17-3.45)$ & $2.05(1.15-3.67)^{*}$ \\
\hline High & $174(50.9)$ & 168(49.1) & $7.40(4.48-12.22)$ & $4.75(2.76-8.18)^{*}$ \\
\hline \multicolumn{5}{|c|}{ History of mental illness } \\
\hline Yes & $33(32.4)$ & $69(67.6)$ & $6.13(3.91-9.60)$ & $4.04(2.40-6.79)^{*}$ \\
\hline No & $519(74.6)$ & $177(25.4)$ & $1.00^{+}$ & $1.00^{+}$ \\
\hline \multicolumn{5}{|c|}{ History of medical illness } \\
\hline Yes & $73(59.8)$ & $49(40.2)$ & $1.63(1.09-2.43)$ & $1.42(0.87-2.32)$ \\
\hline No & $479(70.9)$ & $197(29.1)$ & $1.00^{+}$ & $1.00^{+}$ \\
\hline \multicolumn{5}{|l|}{ Khat } \\
\hline Yes & $148(64.9)$ & $80(35.1)$ & $1.31(0.94-1.82)$ & I.17(0.79-1.73) \\
\hline No & $404(70.9)$ & $166(29.1)$ & $1.00^{+}$ & $1.00^{+}$ \\
\hline
\end{tabular}

Notes: *Adjusted for all significant variables $\mathrm{p}<0.05,1.00^{+}$Reference Category.

These finding were lower in a recently published study in India in response to the COVID-19 pandemic, where it reported the level of anxiety, depression, and stress were $43 \%, 39 \%$, and $36 \%$, respectively. ${ }^{29}$ The lower prevalence in our study could be attributed to the early day of the outbreak when only a few cases had been reported in Ethiopia, the majority of the cases reported were imported from abroad. It might be also the effect of a nationwide lockdown on Indian study participants.

Contrary to our findings, significantly lower proportions of anxiety (10.8\%), depression $(8.1 \%)$, and stress $(6.4 \%)$ were found among health care workers in Singapore. ${ }^{30}$ The possible reason for this could be a difference in the study population. Health care workers have first-hand medical information about the outbreak, disease characteristics and its prevention mechanisms. It could be attributed to increase mental preparedness for the outbreak in Singapore after the previous SARS outbreak experience. $^{30}$

Positive anxiety and depression were found to be strongly linked to sex. Female was two times more likely to develop anxiety and depression compared to males. This finding is in agreement with studies done in India, Iran, and China. ${ }^{18,31-33}$ The possible rationale might be that women are more vulnerable to the socio-cultural risk factors associated with mental impact. Compared to males, 
Table 5 Factor Associated with Stress Among Participants' During the COVID-19 Outbreak Among the Pastoral Community in West Omo Zone, South-West Ethiopia, 2020

\begin{tabular}{|c|c|c|c|c|}
\hline \multirow[t]{2}{*}{ Variables } & \multicolumn{2}{|c|}{ Stress } & \multirow[t]{2}{*}{ COR at $95 \% \mathrm{Cl}$} & \multirow[t]{2}{*}{ AOR at $95 \% \mathrm{Cl}$} \\
\hline & No (\%) & Yes (\%) & & \\
\hline \multicolumn{5}{|l|}{ Sex } \\
\hline Male & $337(78.6)$ & $92(21.4)$ & $1.00^{+}$ & $1.00^{+}$ \\
\hline Female & $266(72.1)$ & $103(27.9)$ & $1.41(1.02-1.96)$ & $1.39(0.94-2.06)$ \\
\hline \multicolumn{5}{|l|}{ Family Size } \\
\hline One & $232(80.3)$ & $57(19.7)$ & $1.00^{+}$ & $1.00^{+}$ \\
\hline Two & $|8|(77.0)$ & $54(23.0)$ & $1.21(0.79-1.84)$ & $0.89(0.55-1.47)$ \\
\hline Three and More & $190(69.3)$ & $84(30.7)$ & $1.79(1.22-2.65)$ & $0.96(0.60-1.53)$ \\
\hline \multicolumn{5}{|l|}{ Social Support } \\
\hline Poor & $210(57.9)$ & $153(42.1)$ & $9.13(5.00-16.68)$ & $5.74(2.98-11.04)^{*}$ \\
\hline Moderate & $230(88.8)$ & $29(11.2)$ & $1.58(0.79-3.13)$ & $1.91(0.91-3.98)$ \\
\hline Strong & $163(92.6)$ & $13(7.4)$ & $1.00^{+}$ & $1.00^{+}$ \\
\hline \multicolumn{5}{|c|}{ Perceived life threat } \\
\hline Low & $169(92.9)$ & $13(7.1)$ & $1.00^{+}$ & $1.00^{+}$ \\
\hline Medium & $247(90.1)$ & $27(9.9)$ & I.42(0.7I-2.83) & $1.70(0.81-3.53)$ \\
\hline High & $187(54.7)$ & $155(45.3)$ & $10.77(5.89-19.69)$ & $6.88(3.63-13.03)^{*}$ \\
\hline \multicolumn{5}{|c|}{ History of mental illness } \\
\hline Yes & $4 I(40.2)$ & $61(59.8)$ & $6.24(4.02-9.67)$ & $3.63(2.15-6.12)^{*}$ \\
\hline No & $562(80.7)$ & $134(19.3)$ & $1.00^{+}$ & $1.00^{+}$ \\
\hline \multicolumn{5}{|c|}{ History of medical illness } \\
\hline Yes & $85(69.7)$ & $37(30.3)$ & $1.42(0.93-2.18)$ & $1.06(0.62-1.82)$ \\
\hline No & $518(76.6)$ & $158(23.4)$ & $1.00^{+}$ & $1.00^{+}$ \\
\hline \multicolumn{5}{|c|}{ Average monthly Income } \\
\hline$<2001$ & $237(73.1)$ & $87(26.9)$ & $0.80(0.58-I . I I)$ & $0.72(0.48-1.07)$ \\
\hline$\geq 200$ I & $366(77.2)$ & $108(22.8)$ & $1.00^{+}$ & $1.00^{+}$ \\
\hline \multicolumn{5}{|l|}{ Alcohol use } \\
\hline Yes & $26 \mid(73.3)$ & $95(26.7)$ & $1.24(0.90-1.72)$ & $1.35(0.90-2.03)$ \\
\hline No & $342(77.4)$ & $100(22.6)$ & $1.00^{+}$ & $1.00^{+}$ \\
\hline \multicolumn{5}{|l|}{ Khat use } \\
\hline Yes & $164(71.9)$ & $64(28.1)$ & $1.30(0.92-1.85)$ & $1.24(0.80-1.91)$ \\
\hline No & $439(77.0)$ & $131(23.0)$ & $1.00^{+}$ & $1.00^{+}$ \\
\hline
\end{tabular}

Notes: *Adjusted for all significant variables $\mathrm{p}<0.05,1.00^{+}$Reference Category.

females experience more fluctuations of hormone levels that are associated with emotional symptoms. ${ }^{34}$ It has been that common mental illness such as depression and anxiety are more prevalent in women. ${ }^{35}$ Moreover, it should be noted that a higher rate of domestic violence against women was reported during this outbreak. ${ }^{36}$

This study found that respondents who had two or more family members were more likely to have positive anxiety compared with those who had one family member. This result is supported by studies done in Addis Ababa, Ethiopia, ${ }^{22}$ and China. ${ }^{18}$ This might be explained by households with large family members may have more contact with different people in their daily activities; this may increase their worry about getting the disease since the virus is highly contagious through personal contact. Long-term confinement at home has an impact on the relationships between family members, given that conflict may increase in this unusual and stressful situation. ${ }^{37}$

Respondents who had a previous history of mental illness were more likely to develop probable depression, anxiety and stress than their counterparts. People with a history of mental illness are more susceptible to the 
psychological impact compared to the general public, such an outbreak can provoke a relapse or even worsen the already existing psychological problem. ${ }^{38}$ The result is in agreement with other studies done in Ethiopia ${ }^{23}$ and China. $^{18}$

Similarly, people with low to moderate social support were more likely to suffer from depression, anxiety, and stress than those with good social support. This is in line with studies done in China, ${ }^{39}$ Ethiopia, ${ }^{40}$ and Kenya. ${ }^{26}$ The possible reason might be the feeling of being loved and wanted may contribute to a supportive environment which would help individuals to cope with different psychosocial challenges.

Having high perceived life threat was more likely to have positive depression, anxiety, and stress. This finding was in line with a similar study done in Iran, ${ }^{41}$ and the United States where the prevalence of depression, and stress was more common among respondents with positive perceived life threat. ${ }^{42}$ The reason might be due to the pandemic causing feelings of susceptibility and loss of control of self, and family life could be complicated. It is likely that people within such an outbreak are afraid of contracting the coronavirus, have a fear of falling sick, suffering with feelings of hopelessness, worry about stigma and even death. ${ }^{43}$

\section{Conclusion and Recommendation}

The prevalence of depression, anxiety, and stress was found to be high among pastoral communities in the West Omo zone of south-west Ethiopia, according to the report. Female gender, a history of mental illness, a lack of social support, and a high perceived stigma were all related to depression, anxiety, and stress.

Compared to the general population, the pastoral community is neglected and mostly found rural areas, which are not accessible for updated information. So the Ethiopian government and other local governmental organizations should give special attention to psychosocial and mental health programs alongside other medical services. Moreover, mechanisms should be designed to provide accurate information through different media outlets with local languages to reduce the psychological impacts related to misinformation.

Psychosocial intervention by mental health specialists should be designed directly for pastoral dwellers, basically for female adults who had a history of mental illness, individuals with poor social support and high perceived stigma. Researchers should conduct a longitudinal study in order to know the long-term impact of the COVID 19 pandemic on people's mental health in the pastoral community.

\section{Study Limitation}

This study was conducted at the early stage of COVID-19 pandemic, which may have underestimated prevalence of anxiety, depression and stress. Second, there might be social desirability bias regarding to the question assess about substance use. Furthermore, the data is cross-sectional, making it difficult to draw conclusions about the direction of relationships among study variables.

\section{Abbreviations}

AOR, adjusted odds ratio; CL, confidence level; COVID 19, Novel Corona Virus 2019; EPHA, Ethiopia Public Health Association; MERS, Middle East Respiratory Syndrome; MHI, mental health impact; PSS, perceive life threat; SARS, severe acute respiratory syndrome; UNISDR, United Nation Office for Disaster Risk Reduction; WHO, World Health Organization.

\section{Data Sharing Statement}

The first author will make the datasets generated and analyzed during the study accessible to organizations and individuals upon appropriate request.

\section{Ethical Approval and Consent to Participate}

Ethical assurance was obtained from Mizan-Tepi University research ethical review board (IRB) (Ref No: MTU/20/45/8/26/12). After explaining the purpose and benefit of the study written informed consent was obtained from each study participants. The participants were informed that they have the right to refuse participation in the study at any time and refusing to participate will not affect them. The interview with study participants was conducted with strict privacy and confidentiality. Moreover this study was conducted in accordance with the Declaration of Helsinki.

\section{Acknowledgments}

First and foremost, we would like to thank Mizan Tepi University's research directorate for giving us the opportunity to write this article. Without the data collectors, supervisor, and study participants, the analysis would not have been possible. 


\section{Funding}

This study was not funded by any organizations.

\section{Disclosure}

The authors declare that they have no conflicts of interest for this work.

\section{References}

1. World Health Organization. Coronavirus disease(COVID-19) outbreak; 2020. Available from: https://www.who.int/images/default-source/ health-topics/coronavirus/gettyimages-1203376093.tmb-1920v.png? Culture=en\&sfvrsn=6e0c1bc7_61920w. Accessed June 5, 2021.

2. World Health Organization. Coronavirus $\mid$ WHO $\mid$ regional office for Africa; 2021. Available from: https://www.afro.who.int/publications/ coronavirus. Accessed June 5, 2021.

3. Mohamed AA. Pastoralism and development policy in Ethiopia: a review study. Budapest Int Res Crit Inst Humanit Soc Sci. 2019;2 (4):01-11.

4. The Federal Democratic Republic of Ethiopia Ministry of Agriculture. Regional pastoral livehoods resilince- resettlement policy framework; 2013. Available from: https://ewsdata.rightsindevelop ment.org/files/documents/06/WB-P150006_6Uj7vg8.pdf. Accessed June 5, 2021.

5. Desta S. Pastoralism and development in Ethiopia. Econ Focus. 2006;9(3):12-20

6. Smith L, Frankenberger T, Langworthy B, Martin S, Spangler T, Nelson S. Ethiopia Pastoralist Areas Resilience Improvement and Market Expansion (PRIME) project impact evaluation baseline survey report volume 1. Main Rep. 2015;1(January):1-155.

7. World Bank Group. Pastoral community development project: phases I and II. Project Perform Assess Rep. 2016;(104210):109

8. World Health Organization. WHO Director-General's opening remarks at the mission briefing on COVID-19; 2020. Available from: https://www.who.int/dg/speeches/detail/who-director-generals-opening-remarks-at-the-mission-briefing-on-covid-19-12-march2020. Accessed June 5, 2021.

9. Sohrabi C, Alsafi Z, Neill NO, et al. World Health Organization declares global emergency: a review of the 2019 novel coronavirus (COVID-19). Int J Surg. 2020;76(February):71-76. doi:10.1016/j. ijsu.2020.02.034

10. Sohrabi C, Alsafi Z, Neill NO, Khan M, Kerwan A. Since January 2020 Elsevier has created a COVID-19 resource centre with free information in English and Mandarin on the novel coronavirus COVID- 19. The COVID-19 resource centre is hosted on Elsevier Connect, the company ' s public news and information. Int J Surg. 2020.

11. World Health Organization. Coronavirus; 2020. Available from: https://www.who.int/health-topics/coronavirus\#: : text= Coronavirusdisease(COVID-19)isaninfectiousdiseasecaused,recover withoutrequiringspecialtreatment. Accessed June 5, 2021.

12. World Health Organization. Report of the WHO-China joint mission on Coronavirus disease 2019 (COVID-19). Vol. 2019; 2020. Available from: https:/www.who.int/docs/default-source/coronavir use/who-china-joint-mission-on-covid-19-final-report.pdf. Accessed June 5, 2021.

13. Conditions CM. COVID-19 people with certain medical conditions reduce your risk of getting COVID-19; 2021. 1-11. Available from: https://www.cdc.gov/coronavirus/2019-ncov/need-extra-precautions/ people-with-medical-conditions.html. Accessed June 5, 2021.

14. Worldometr. COVID-19 CORONAVIRUS (/CORONAVIRUS/ )/CASES UPDATES. Vol. 576; 2020. Available from: https://www. worldometers.info/coronavirus/coronavirus-cases. Accessed June 5, 2021.
15. World Health Organization. COVID-19 WHO Africa region; 2020. Available from: https://www.who.int/emergencies/diseases/novel-cor onavirus-2019/situation-reports. Accessed June 5, 2021.

16. Hwang TJ, Rabheru K, Peisah C, Reichman W, Ikeda M. Loneliness and social isolation during the COVID-19 pandemic. Int Psychogeriatr. 2020;32(10):1217-1220. doi:10.1017/S10416102 20000988

17. Panchal N, Kamal R. The implications of COVID-19 for mental health and substance use; 2020. 1-13. Available from: https://www. kff.org/health-reform/issue-brief/the-implications-of-covid-19-formental-health-and-substance-use/. Accessed June 5, 2021.

18. Cullen W, Gulati G, Kelly BD. Immediate psychological responses and associated factors during the initial stage of the 2019 Coronavirus disease (COVID-19) epidemic among the general population in China Cuiyan. Int J Environ Res Public Health Artic. 2020;113 (5):311-312.

19. Arora T, Grey I, Östlundh L, Lam KBH, Omar OM, Arnone D. The prevalence of psychological consequences of COVID-19: a systematic review and meta-analysis of observational studies. $J$ Health Psychol. 2020;135910532096663. doi:10.1177/13591053 20966639

20. Chen J, Farah N, Dong RK, et al. The mental health under the COVID-19 crisis in Africa: a systematic review and meta-analysis. BMJ Open. 2021;1-34. doi:10.1101/2021.04.19.21255755.

21. Clair R, Gordon M, Kroon M, Reilly C. The effects of social isolation on well-being and life satisfaction during pandemic. Human Soc Sci Commun. 2021;8(1):1-6. doi:10.1057/s41599-021-00710-3

22. Kassaw C. The magnitude of psychological problem and associated factor in response to COVID-19 pandemic among communities living in Addis Ababa, Ethiopia, March 2020: a cross-sectional study design. Psychol Res Behav Manag. 2020;13:631-640. doi:10.2147/ PRBM.S256551

23. Birhanu A, Tiki T, Mekuria M, Yilma D, Melese G, Seifu B. COVID19-induced anxiety and associated factors among urban residents in West Shewa Zone, Central Ethiopia, 2020. Psychol Res Behav Manag. 2021;14:99-108. doi:10.2147/PRBM.S298781

24. Fisher J, Thach DT, Tuan T. Validation of the depression anxiety stress scales (DASS) 21 as a screening instrument for depression and anxiety in a rural ... Validation of the depression anxiety stress scales (DASS) 21 as a screening instrument for depression and anxiety in a rur. BMC Psychiatr. 2013;13(24):1-7. doi:10.1186/1471-244X-13-1

25. Kocalevent RD, Berg L, Beutel ME, et al. Social support in the general population: standardization of the Oslo social support scale (OSSS-3). BMC Psychol. 2018;6(1):4-11. doi:10.1186/s40359-0180249-9

26. Pérez-Fuentes MC, Molero Jurado MM, Oropesa Ruiz NF, et al. Questionnaire on perception of threat from COVID-19. J Clin Med. 2020;9(4):1196. doi: $10.3390 /$ jcm9041196

27. Alkhamees AA, Alrashed SA, Alzunaydi AA. The Psychological Impact of COVID-19 Pandemic on the General Population of Saudi Arabia. ELISEVIER; 2020.

28. Odriozola-González P, Planchuelo-Gómez Á, Irurtia-Muñiz MJ, de Luis-garcía R. Psychological symptoms of the outbreak of the COVID-19 crisis and confinement in the population of Spain; 2020. Available from: https://psyarxiv.com/mq4fg/. Accessed June 5, 2021.

29. Zaytsev P, Hasaneini SJ, Ruina A. COVID-19 and lockdown: a study on the impacts on mental health. SSRN; 2020; Available from: https://papers.ssrn.com/sol3/papers.cfm?abstract_id=3577515. Accessed June 5, 2021.

30. Tan BYQ, Chew NWS, Lee GKH, et al. Psychological impact of the COVID-19 pandemic on health care workers in Singapore. Ann Intern Med. 2020;173(4):317-320. doi:10.7326/M20-1083

31. Shahriarirad R, Erfani A, Ranjbar K, Bazrafshan A, Mirahmadizadeh A. The mental impact of COVID-19 outbreak: a population-based survey in Iran. Res Sq. 2020;1-22. 
32. Rajkumar RP. COVID-19 and mental health: a review of the existing literature. Asian J Psychiatr. 2020;52(March):1-5. doi:10.1016/j. ajp.2020.102066

33. Gao W, Ping S, Liu X. Gender differences in depression, anxiety, and stress among college students: a longitudinal study from China. J Affect Disord. 2020;263:292-300. doi:10.1016/j.jad.2019.11.121

34. Soares CN, Zitek B. Reproductive hormone sensitivity and risk for depression across the female life cycle: a continuum of vulnerability? J Psychiatry Neurosci. 2008;33(4):331-343.

35. Mistral W. Mental health and substance use [Internet]. Vol. 17, World Health Organization; 2011. Available from: https://www.who.int/ teams/mental-health-and-substance-use/gender-and-women-s-mentalhealth. Accessed June 5, 2021.

36. Organization F. AFRICA/ETHIOPIA - violence on women and girls increases: the effects of Covid-19; 2020. Available from: http://www. fides.org/en/news/68330-AFRICA_ETHIOPIA_Violence_on_ women_and_girls_increases_the_effects_of_Covid_19. Accessed June 5, 2021.

37. Vieira CM, Franco OH, Restrepo CG, Abel T. COVID-19: The Forgotten Priorities of the Pandemic. ELSEVER; 2020.

38. Holmes EA, O'Connor RC, Perry VH, et al. Multidisciplinary research priorities for the COVID-19 pandemic: a call for action for mental health science. Lancet Psychiatr. 2020;7(6):547-560. doi:10.1016/S2215-0366(20)30168-1
39. Qi M, Zhou SJ, Guo ZC, et al. The effect of social support on mental health in chinese adolescents during the outbreak of COVID-19. J Adolesc Health. 2020;67(4):514-518. doi:10.1016/j.jadohealth.20 20.07.001

40. Elvira SD, Lamuri A, Lukman PR, Malik K, Shatri H, Abdullah M. Psychological distress among Greater Jakarta area residents during the COVID-19 pandemic and community containment. Heliyon. 2021;7(2):e06289. doi:10.1016/j.heliyon.2021.e06289

41. Khademian F, Delavari S, Koohjani Z, Khademian Z. An investigation of depression, anxiety, and stress and its relating factors during COVID-19 pandemic in Iran. BMC Public Health. 2021;21(1):1-7. doi:10.1186/s12889-021-10329-3

42. Kalia V, Knauft K, Hayatbini N, Santana GL. Cognitive flexibility and perceived threat from COVID-19 mediate the relationship between childhood maltreatment and state anxiety. PLoS One. 2020;15(12):1-18. doi:10.1371/journal.pone.0243881

43. Levkovich I, Shinan-Altman S, Bygbjerg IC. Impact of the COVID-19 pandemic on stress and emotional reactions in Israel: a mixed-methods study. Int Health. 2020;12:1-9. doi:10.1093/ inthealth/ihz011
Psychology Research and Behavior Management

\section{Publish your work in this journal}

Psychology Research and Behavior Management is an international, peer-reviewed, open access journal focusing on the science of psychology and its application in behavior management to develop improved outcomes in the clinical, educational, sports and business arenas. Specific topics covered in the journal include: Neuroscience, memory and decision making; Behavior modification and management; Clinical

\section{Dovepress}

applications; Business and sports performance management; Social and developmental studies; Animal studies. The manuscript management system is completely online and includes a very quick and fair peer-review system, which is all easy to use. Visit http://www. dovepress.com/testimonials.php to read real quotes from published authors. 